\title{
EROSÃO HÍDRICA EM CAMBISSOLO HÚMICO ALUMÍNICO SUBMETIDO A DIFERE NTES SISTEMAS DE PREPARO E CULTIVO DO SOLO: I. PERDAS DE SOLO E ÁGUA ${ }^{(1)}$
}

\author{
J.SCHICK(2), I. BERTOL (3), \\ O. BATISTELA(4) \& A. A. BALBINOT J ÚNIOR ${ }^{(4)}$
}

\begin{abstract}
RESUMO
O impacto das gotas de chuva e o escoamento superficial são os agentes ativos na erosão hídrica, a qual é fortemente influenciada pela cobertura e rugosidade do solo, tipo de cultura e sistema de preparo. Os preparos conservacionistas diminuem a erosão hídrica em relação aos preparos convencionais, por meio da cobertura e rugosidade superficial. Com o objetivo de quantificar as perdas de solo e água sob chuva natural, nos sistemas de preparo: aração + duas gradagens, escarificação + gradagem e semeadura direta, executados no sentido paralelo ao declive, ambos com rotação e sucessão de culturas, realizou-se um trabalho no Campus do Centro de Ciências Agroveterinárias de Lages (SC), no período de janeiro de 1993 a outubro de 1998. Na rotação, foram utilizadas as culturas de soja, aveia preta, feijão, ervilhaca comum, milho, ervilhaca comum, soja, trigo, feijão, nabo forrageiro, milho e aveia preta e, na sucessão, trigo e soja em todos os anos. 0 outro tratamento constou de solo sem cultura, preparado com aração + duas gradagens no sentido paralelo ao declive. Utilizou-se um Cambissolo Húmico alumínico argi loso, com 0,102 $\mathrm{m} \mathrm{m}^{-1}$ de declividade média. A semeadura di reta, na média da rotação e sucessão de culturas, reduziu as perdas de solo em 52, 68 e 98\% em relação à escarificação + gradagem, aração + duas gradagens e aração + duas gradagens no solo sem cultura, respectivamente. Na primavera-verão, as perdas de solo foram $63 \%$ mai ores do que no outono-inverno, na média dos tratamentos estudados. A rotação de culturas reduziu as perdas de solo em $37 \%$ em relação à sucessão, na média dos tratamentos de preparo do solo com culturas. $\mathbf{O}$ sistema de cultivo influenciou mais fortemente as perdas de solo quando o preparo do solo constou de aração + duas gradagens. As perdas de água comportaram-se de maneira semelhante às perdas de solo, diferindo quanto à magnitude dos seus valores.
\end{abstract}

Termos de indexação: preparo conservacionista, rotação de culturas, sucessão de culturas, semeadura direta.

\footnotetext{
(1) Parte da Tese de Mestrado do primeiro autor, apresentada à Faculdade de Agronomia do CAV/UDESC, Lages (SC), como um dos requisitos para conclusão do Curso de Mestrado em Ciência do Solo. Executado com recursos parciais da FINEP/CAPES/UDESC. Recebido para publicação em agosto de 1999 e aprovado em fevereiro de 2000.

(2) Pós-Graduando em Agronomia do CAV/UDESC. Caixa Postal 281, CEP 88520-000 Lages (SC). Bolsista do CNPq.

(3) Professor do Centro de Ciências Agroveterinárias, UDESC. Bolsista do CNPq. E-mail a2ib@cav.udesc.br.

(4) Graduando em Agronomia do CAV/UDESC. Bolsista de Iniciação Científica PIBIC.
} 


\title{
SUMMARY: WATER EROSION IN CLAYEY INCEPTISOL IN DIFFERENT CROP AND TILLAGE SYSTEMS:I. SOIL AND WATER LOSSES
}

\begin{abstract}
Raindrop impact and run off are theactiveagents of water erosi on, which is influenced by soil roughness and cover, crop typeand tillagesystem. Conservation tillagereduces water erosion in relation to conventional tillage by means of surface roughness and cover. This work was conducted in Centro deCiência Agroveterinárias, in Lages, Santa Catarina, Brazil, fromJ anuary 1993, to October 1998 to quantify soil and runoff losses under natural rainfall in the following soil tillage downslope systems: no-tillage, chisel plow plus disking and plowing plus disking, both on crop rotation and succession, and onebaresoil tillagetreatment with plowing plus disking. Soybean, oat, bean, vetch, corn, vetch, soybean, wheat, bean, fodder radish, corn and oat were cropped in rotation and wheat and soybean in crop succession. Thesoil was a clayey I nceptisol (Haplumbrept) with a slope of $0.102 \mathrm{~m} \mathrm{~m}^{-1}$. The no-tillagesystem reduced soil l osses in 52, 68 and $98 \%$ in relation to chisel pl us disking, and plowing plus disking and bare soil, respectively. Soil losses were 63\% lower in the springsummer than in theautumn-winter period. Soil losses werereduced by $37 \%$ with crop rotation in relation to crop succession, on the average of the soil tillage systems used in the trial. Water losses weresimilar to soil losses, differing in their magnitude.
\end{abstract}

Index terms: conservation tillage, crop rotation, crop succession, no-tillage.

\section{NTRODUÇÃO}

A erosão hídrica é um processo complexo que se manifesta em intensidade variável, dependendo da importância relativa do clima, solo, topografia, vegetação e uso do solo, práticas conservacionistas complementares eatividade do homem. Dentro desse contexto, a cobertura do solo é o fator isolado mais importante (F oster, 1982), mas a rugosidade e as propriedades físicas da superfície (Cogo, 1981) e subsuperfície (Allmaras et al., 1966) também afetam fortemente a erosão.

O preparo do solo normalmente incorpora os resíduos culturais e altera as propriedades físicas da superfície e subsuperfície, favorecendo a erosão hídrica. De modo geral, o aumento na intensidade do preparo diminui a cobertura, a rugosidade e a porosidade total da camada preparada (Burwell et al., 1963), aumentando a erosão hídrica (Cogo, 1981). No entanto, a incorporação ao solo de grandes quantidades de resíduos culturais pode reduzir as perdas de solo nos preparos mais intensos (Foster, 1982). I sso se deve, sobretudo, ao efeito mecânico ocasionado pelo "ancoramento" do resíduo eao efeito biológico devido à atividade microbiana sobre a estrutura do solo. Assim, é possível que sistemas de preparo de solo relativamente mais intensos apresentem perdas de solo relativamente baixas, como constatado por Bertol (1994).

Os sistemas de preparo conservacionistas caracterizam-se por uma reduzida movimentação do solo, preservação da cobertura pel os resíduos vegetais na superfície e, com exceção da semeadura direta, elevada rugosi dade, reduzindo a erosão hídrica (Cogo et al., 1984; Bertol, 1995; Hernani et al., 1997).

A semeadura direta, apesar da baixa rugosidade superficial, possibilita o “ancoramento" dos resíduos vegetais nas soqueiras das culturas e, ainda, apresenta el evada consolidação da superfície (Dissmeyer \& Foster, 1981). Isso aumenta a tensão crítica decisal hamento do sol o e, conseqüentemente, sua resistência à erosão hídrica (Cogo, 1981; Bertol, 1995).

Sistemas de manejo que mantêm os resíduos culturais na superfície são mais eficazes no controle das perdas de solo e água do que aqueles em que os resíduos são total ou parcialmente incorporados (Carvalho et al., 1990; Bertol et al., 1997; Hernani et al., 1997). Por outrolado, as perdas deágua, em geral, são menos afetadas do que as perdas de solo pelos sistemas de preparo e manejo utilizados (Cogo et al., 1984; Bertol et al., 1997). I sto se deve ao fato de o solo apresentar limitada capacidade de infiltração deágua, a partir da qual a taxa de enxurrada tendea se igualar em sistemas de preparo e manejo distintos (Bertol, 1994).

A rotação de culturas, caracterizada por um sistema de cultivo baseado na alternância de espécies vegetais, planejada e recorrente no tempo e no espaço, melhora, em geral, as condições físicas e quími cas do solo, as quais concor rem para a redução da erosão hídrica (Uhland, 1949; Moldenhauer et al., 1967; Lombardi Neto, 1994).

O presentetrabal hoteveo objetivo decorrelacionar as perdas de solo e água sob chuva natural, num Cambissol o Húmicoalumínico em Lages (SC) submetido a diversos sistemas de preparo e cultivo do solo. 


\section{MATE RIAL E MÉTODOS}

O experimento foi realizado entrejaneiro de 1993 e outubro de 1998, no Campus do Centro de Ciências Agroveterinárias de Lages (SC), situado a 270 49' de latitude sul e 5020' de longitude oeste, a $937 \mathrm{~m}$ de altitudemédia, na região do PlanaltoSul Catarinense, onde o clima é do tipo Cfb, segundo a classificação de Köppen, com uma precipitação média anual de $1600 \mathrm{~mm}$. O solo no local do experimento é um Cambissol o Húmico al umínico argil oso horizonte A moderado, com substrato composto de siltitos + argil itos e declividade média de 0,102 $\mathrm{m} \mathrm{m}^{-1}$, descrito em Bertol (1994).

A área experimental foi inicialmente utilizada em pastagem cultivada (gramíneas e leguminosas consorciadas) durante quatro anos, antes de ser destinada (outubro de 1988) ao estudo da erosão. Antes do experimento, a área foi corrigida com calcário para elevar opH do solo a 6,0.

De outubro de 1988 a novembro de 1992, as parcelas de erosão foram cultivadas com a sucessão de culturas milho/trigo/milho e, a partir daí, introduziu-se uma rotação de culturas em uma das repetições de preparo do solo. Desde então, a área experimental vem sendo utilizada para o presente estudo, com os tratamentos de preparo do sol o sem repetição (duas repetições no solo sem cultura), distribuídos ao acaso, executados no sentido longitudinal ao declive, conforme a filosofia de obtenção dos dados para a Equação Universal de Perda de Solo (EUPS).

Os tratamentos de preparo do solo consistiram em: solo sem cultura, preparado com uma aração + duas gradagens duas vezes ao ano, na mesma época de preparo do solo e semeadura das culturas nos demais tratamentos, mantido livre de vegetação e de crosta superficial (parcela-padrão da EUPS); preparo convencional com sucessão de culturas (uma aração + duas gradagens duas vezes ao ano); preparo convencional com rotação de culturas (uma aração + duas gradagens duas vezes ao ano); cultivo mínimo com sucessão de culturas (uma escarificação + uma gradagem duas vezes ao ano); cultivo mínimo com rotação de culturas (uma escarificação + uma gradagem duas vezes ao ano); semeadura direta com sucessão de culturas (sem preparo do solo); e semeadura direta com rotação de culturas (sem preparo do solo). A rotação de culturas consistiu no cultivo de soja (Glycine max), feijão (Phaseol us vulgaris), milho (Zea mays), soja, feijão e milho, na primavera-verão, e aveia preta (Avena sativa), ervilhaca comum (Vicia sativa L.), ervilhaca comum, trigo (Triticumaestivum L.), nabo forrageiro (Raphanus sativus L.) e aveia preta, no outonoinverno. A sucessão de culturas consistiu no cultivo de soja, na primavera-verão, e de trigo, no outonoinverno.
As culturas de soja, feijãoe milhoforam semeadas em linha com espaçamentos de 0,5, 0,4 e 1,0 m, respectivamente (no sentido do declive), com semeadora manual ("saraquá"). As culturas detrigo, aveia preta, ervilhaca comum e nabo forrageiro foram semeadas a lanço.

A unidade experimental abrangeu uma parcela com dimensões de $22,1 \times 3,5 \mathrm{~m}$, delimitada por chapas galvanizadas cravadas $10 \mathrm{~cm}$ no solo e, na sua extremidade inferior, por um sistema col etor de enxurrada, composto de uma calha para receber o material erodido, conectada por um cano de PVC a um primeiro tanque (de sedi mentação), situado $6 \mathrm{~m}$ abaixo da parcela. Este, por sua vez, estava ligado, através de um divisor de enxurrada tipo "Geib", a um segundo tanque (de armazenagem).

A coleta e o processamento das amostras de enxurrada para a quantificação das perdas de sol o e água foram feitas seguindo o método proposto por Cogo (1978). As perdas de sol o observadas no campo foram ajustadas para o declive de $0,09 \mathrm{~m} \mathrm{~m}^{-1}$ (parcela-padrão da EUPS) pela seguinte equação, proposta por Wischmeier \& Smith (1978):

$$
S=0,065+4,56 \operatorname{sen} \theta+65,41 \operatorname{sen}^{2} \theta
$$

sendo:

$\mathrm{S}=$ fator declividade da EUPS, definido pela relação de perda de solo entre uma parcela com declive qualquer (no caso com 0,102 $\mathrm{m} \mathrm{m}^{-1}$ ) e outra com declive de 0,09 $\mathrm{m} \mathrm{m}^{-1}$ (parcela-padrão); e

$\theta=$ ângulo de declive do terreno. Portanto, no caso em questão, a equação final que proporcionou tais ajustes, discutida em Bertol (1994), foi dada por:

sendo:

$$
a_{0,09} m^{-1}=0,8342 \times a_{0,102} \mathrm{~m} \mathrm{~m}^{-1}
$$

$\mathrm{a}_{0,09 \mathrm{~m} \mathrm{~m} \mathrm{~m}^{-1}}=$ perda de solo ocasionada por uma chuva qual quer, ajustada para o declivede $0,09 \mathrm{~m} \mathrm{~m}^{-1}$;

$a_{0,102 m^{-1}}=$ perda de solo ocasionada por uma chuva qualquer, ocorrida no declive de $0,102 \mathrm{~m} \mathrm{~m}^{-1}$ da parcela experimental.

Para o cálculo da erosividade $\left(\mathrm{EI}_{30}\right)$, estudaramse chuvas erosivas individuais, conceituadas por Wischmeier (1959) e Wischmeier \& Smith (1978). Após terem sido cotadas as chuvas em segmentos de intensidade uniforme, calculou-se sua energia cinética por meio de programa computacional (Cataneo et al., 1982), com adaptações de Maria (1994), seguindo-se o método proposto por Wischmeier \& Smith (1958). Utilizou-se a equação sugerida por F oster et al. (1981), a saber:

$$
E=0,119+0,0873 \log _{10} I
$$

sendo:

$$
\mathrm{E}=\text { energia cinética por } \mathrm{mm} \text { de chuva, }
$$
MJ $\mathrm{mm} \mathrm{ha}^{-1} \mathrm{~h}^{-1} \mathrm{e}$

$$
\mathrm{I}=\text { intensidade da chuva, } \mathrm{mm} \mathrm{h}^{-1} \text {. }
$$


A cobertura do solo pelos resíduos culturais remanescentes foi determinada imediatamenteapós o preparo do sol o em cada cultivo (após a semeadura na semeadura direta), com duas repetições por parcela. Para tanto, utilizou-se o método da trena, descrito por Hartwing \& Laflen (1978).

A rugosidade superficial do sol o foi determinada por meio de um perfilômetro, com 41 varetas distanciadas $1,5 \mathrm{~cm}$ entre si, permitindo a tomada deleituras em dez posições di ferentes no mesmo local da parcela, total izando 410 leituras de el evações da superfície do solo, em cada local. F oram realizadas leituras em dois locais na parcela, totalizando 820 leituras por parcela. A rugosidadesuperficial do solo foi representada pelo logaritmo decimal da média do desvio-padrão das alturas das elevações da superfície do solo, conforme Kuipers (1957).

\section{RESULTADOS E DISCUSSÃO}

A quantidade de resíduos culturais agregada ao solo nos tratamentos de preparo submetidos à rotação de culturas foi cerca de $8 \%$ maior do que naquel es submetidos à sucessão (Quadro 1). I sto ocorreu em conseqüência do tipo de cultura utilizado em cada sistema de cultivo.

O sistema aração + duas gradagens proporcionou a menor cobertura do solo pel os resíduos culturais, em ambas as épocas de cultivo estudadas, tanto na rotação quanto na sucessão de culturas, seguido da escarificação + gradagem e semeadura direta
(Quadro 2). A diferença de cobertura do solo proporcionada pelos resíduos culturais nos diferentes sistemas de preparo deveu-se à ação diferenciada dos implementos utilizados. $\mathrm{O}$ aumento na intensidade do preparo reduziu a cobertura, pela incorporação parcial ou total dos resíduos culturais preexistentes ao solo. A aração + duas gradagens reduziu a cobertura em cerca de 90 e $85 \%$ em rel ação à semeadura direta e à escarificação+gradagem, respectivamente, na média da rotação e sucessão de culturas, concordando com Cogo et al. (1984) eBertol (1995). A cobertura do sol o influenciou decisivamente a magnitude das perdas de solo e água, conforme discussão realizada em seguida.

A variabilidade na rugosidade superficial foi pequena antes do preparo do solo, com uma amplitude de 8,5 mm, influenciada pel o sistema de preparo (Quadro 3). I mediatamente após o preparo, a amplitude de variação da rugosidade aumentou para 51,2 mm, com o maior índice ocasionado pela escarificação + gradagem, seguido do solo sem cultura e aração + duas gradagens, os quais foram, respectivamente, cerca de cinco, três e duas vezes maiores do que o da semeadura direta. Os valores de rugosi dade obtidos neste estudo são semel hantes aqueles obtidos por Cogo et al. (1984) eBertol (1995). O fato de a rugosidade ter sido maior na aração + duas gradagens sem culturas do que na aração + duas gradagens com culturas pode ser explicado pela alteração na estrutura que, no primeiro, manifestou-se pelo aumento do entorroamento por ocasião do preparo, o que não ocorreu no segundo tratamento, apesar de ambos terem sido preparados da mesma forma.

Quadro 1. Resídu os secos produzidos pela parte aérea das culturas e mantidos sobre o Cambissolo Húmico alumínico, durante o período de 1993 a 1998, em Lages (SC)

\begin{tabular}{|c|c|c|}
\hline Período de cultivo & Rotação de culturas & Sucessão de culturas \\
\hline & \multicolumn{2}{|c|}{ - $\mathrm{t} \mathrm{ha}^{-1}$} \\
\hline 01/01/93 a 08/06/93 & 3,4 (soja) & 3,4 (soja) \\
\hline 09/06/93 a 17/11/93 & 7,2 (aveia preta) & 6,0 (trigo) \\
\hline $18 / 11 / 93$ a $12 / 07 / 94$ & 0,0 (feijão - retirada) & 3,6 (soja) \\
\hline $13 / 07 / 94$ a $18 / 11 / 94$ & 5,5 (ervilhaca comum) & 6,0 (trigo) \\
\hline $19 / 11 / 94$ a $30 / 07 / 94$ & 7,0 (milho) & 1,8 (soja) \\
\hline 01/08/95 a 30/11/95 & 5,3 (ervilhaca comum) & 6,8 (trigo) \\
\hline 01/12/95 a 30/04/96 & 3,4 (soja) & 3,0 (soja) \\
\hline 01/05/96 a 15/11/96 & 7,7 (trigo) & 6,0 (trigo) \\
\hline 15/11/96 a 30/04/97 & 0,0 (feijão - retirada) & 3,9 (soja) \\
\hline 01/05/97 a 15/11/97 & 8,3 (nabo forrageiro) & 6,0 (trigo) \\
\hline 16/11/97 a 30/04/98 & 7,3 (milho) & 4,7 (soja) \\
\hline 01/05/98 a 30/10/98 & 8,1 (aveia preta) & 7,1 (trigo) \\
\hline Total & 63,2 & 58,3 \\
\hline Diferença & \multicolumn{2}{|c|}{4,9 t ha- $^{-1}(8 \%)$} \\
\hline
\end{tabular}


Quadro 2. Cobertura do solo proporcionada por resíduos vegetais de culturas em rotação e em sucessão, desenvolvidas em duas épocas do ano, obtida imedi atamente após a execução dos diferentes sistemas de preparo(1) em Cambissolo Húmico alumínico, no período de 1993 a 1998, em Lages (SC)

\begin{tabular}{|c|c|c|c|c|c|c|c|c|c|c|c|c|}
\hline \multirow{3}{*}{ Ano } & \multicolumn{6}{|c|}{ Primavera-verão } & \multicolumn{6}{|c|}{ Outono-inverno } \\
\hline & \multicolumn{3}{|c|}{ Rotação } & \multicolumn{3}{|c|}{ Sucessão } & \multicolumn{3}{|c|}{ Rotação } & \multicolumn{3}{|c|}{ Sucessão } \\
\hline & $\mathbf{A}+\mathbf{G}$ & $\mathbf{E}+\mathbf{G}$ & SDI & $\mathbf{A}+\mathbf{G}$ & $\mathbf{E}+\mathbf{G}$ & SDI & $\mathbf{A}+\mathbf{G}$ & $\mathbf{E}+\mathbf{G}$ & SDI & $\mathbf{A}+\mathbf{G}$ & $\mathbf{E}+\mathbf{G}$ & SDI \\
\hline & & & & & & & & & & & & \\
\hline 1993 & $0,05(\mathrm{~S})^{(2)}$ & $0,70(\mathrm{~S})$ & 0,94 (S) & $0,05(\mathrm{~S})$ & $0,70(\mathrm{~S})$ & $0,94(\mathrm{~S})$ & $0,05(A)$ & $0,75(\mathrm{~A})$ & $0,98(\mathrm{~A})$ & $0,10(\mathrm{~T})$ & $0,75(T)$ & $0,98(T)$ \\
\hline 1994 & $0,03(T)$ & $0,25(\mathrm{~T})$ & $0,90(\mathrm{~T})$ & $0,04(\mathrm{~S})$ & $0,73(\mathrm{~S})$ & $0,95(S)$ & $0,10(E)$ & $0,68(E)$ & $0,95(E)$ & $0,12(\mathrm{~T})$ & $0,80(\mathrm{~T})$ & $0,95(T)$ \\
\hline 1995 & $0,06(M)$ & 0,75 (M) & $0,97(\mathrm{M})$ & 0,05 (S) & $0,76(\mathrm{~S})$ & 0,98 (S) & $0,12(E)$ & $0,67(\mathrm{E})$ & $0,98(E)$ & $0,30(E)$ & $0,85(E)$ & $0,97(E)$ \\
\hline 1996 & $0,04(\mathrm{~S})$ & $0,72(\mathrm{~S})$ & $0,96(\mathrm{~S})$ & $0,04(\mathrm{~S})$ & $0,75(S)$ & $0,97(S)$ & $0,10(\mathrm{~T})$ & $0,70(\mathrm{~T})$ & $0,96(\mathrm{~T})$ & $0,15(T)$ & $0,78(\mathrm{~T})$ & $0,96(\mathrm{~T})$ \\
\hline 1997 & $0,07(\mathrm{~T})$ & $0,33(\mathrm{~T})$ & $0,96(T)$ & $0,15(S)$ & $0,68(S)$ & $0,96(\mathrm{~S})$ & $0,42(\mathrm{~N})$ & $0,75(\mathrm{~N})$ & $0,98(N)$ & $0,28(T)$ & $0,80(\mathrm{~T})$ & $0,98(T)$ \\
\hline 1998 & $0,06(\mathrm{M})$ & $0,80(\mathrm{M})$ & $0,95(\mathrm{M})$ & $0,03(\mathrm{~S})$ & $0,75(\mathrm{~S})$ & 0,95 (S) & $0,12(\mathrm{~A})$ & $0,73(A)$ & $0,98(A)$ & $0,09(T)$ & $0,71(\mathrm{~T})$ & $0,85(T)$ \\
\hline Média & 0,05 & 0,59 & 0,95 & 0,06 & 0,73 & 0,96 & 0,15 & 0,71 & 0,97 & 0,17 & 0,78 & 0,95 \\
\hline $\mathrm{DP}^{(3)}$ & 0,01 & 0,22 & 0,02 & 0,04 & 0,03 & 0,01 & 0,12 & 0,03 & 0,01 & 0,08 & 0,04 & 0,05 \\
\hline C.V. $(\%)^{(4)}$ & 27 & 37 & 2 & 67 & 4 & 1 & 80 & 4 & 1 & 47 & 5 & 5 \\
\hline
\end{tabular}

(1) Sistemas de preparo do sol o: SDI : semeadura direta; E + G: escarificação + gradagem; A + G: aração + duas gradagens. ${ }^{(2)}$ Letras entre parênteses indicam o cultivo de S: soja; T: trigo; A: aveia preta; F: feijão; E: ervilhaca comum; M: milho; N: nabo forrageiro. (3) DP: desvio-padrão. ${ }^{(4)}$ CV: coeficiente de variação.

Quadro 3. Rugosidade superficial ${ }^{(1)}$, avaliada imediatamente antes do preparo do solo (30/11/95), imediatamente após o preparo (04/12/95), 30 dias após o preparo (03/01/96, com 126,1 mm de chuva precipitada no período) e 140 dias após o preparo (01/05/96, com 625,5 mm de chuva precipitada no período), em diferentes sistemas de preparo ${ }^{(2)}$ de um Cambissolo Húmico alumínico em Lages (SC)

\begin{tabular}{lcccc}
\hline $\begin{array}{c}\text { Sistema } \\
\text { de preparo }\end{array}$ & $\begin{array}{c}\text { Imediatamente antes } \\
\text { do preparo }\end{array}$ & $\begin{array}{c}\text { Imediatamente } \\
\text { após o preparo }\end{array}$ & $\begin{array}{c}\mathbf{3 0} \text { dias } \\
\text { após o preparo }\end{array}$ & $\begin{array}{c}140 \text { dias } \\
\text { após o preparo }\end{array}$ \\
\hline & & & & \\
SDI & 12,5 & 12,5 & 11,5 & 3,5 \\
SSC & 15,5 & 43,0 & 15,5 & 3,2 \\
A + G & 13,8 & 25,5 & 15,9 & 4,8 \\
E + G & 21,0 & 63,7 & 40,6 & 25,0
\end{tabular}

\footnotetext{
(1)M édia da el evação da superfície do terreno coberto com resíduos de ervilhaca (rotação de culturas) e de trigo (sucessão de culturas). ${ }^{(2)}$ Sistemas de preparo do sol o: SDI - semeadura direta; SSC - sol o sem culturataração + duas gradagens; A + G - aração + duas gradagens; E +G - escarificação + gradagem.
}

As chuvas ocasionaram expressivas reduções na rugosidadesuperficial do sol o(Quadro 3), decorrentes do desgaste que elas ocasionaram no solo das microelevações, depositando-o nas microdepressões (Römkens \& Wang, 1987). As menores reduções relativas da rugosidade ocorreram na escarificaçã̃o + gradagem esemeadura direta, explicadas pela maior cobertura do solo nesses tratamentos (Quadro 2). Contribuiu para isso, provavelmente, a melhor deposição dos resíduos culturais sobre a superfície do solo após a ocorrência das chuvas, uma vez que, quando mantidos sobre a superfície, influíram na rugosidade, interagindo com o preparo do sol o (Cogo, 1981; Bertol, 1995). Cento e quarenta dias após o preparo do solo, a amplitude de variação na rugosidade entre os tratamentos era de $21,8 \mathrm{~mm}$ e, com exceção da escarificação + gradagem, praticamente não havia diferença de rugosidade entre os diferentes sistemas de preparo estudados.

Na média do período experimental e agregando os val ores de rotação esucessão de culturas, a perda de sol o na aração + duas gradagens sem cultura foi cerca de 15, 22 e 47 vezes maior do que a com 
aração + duas gradagens, escarificação + gradagem e semeadura direta, respectivamente (Quadro 4), concordando com Bertol (1994). I sto éexplicado pela ausência de cobertura do solo naquele tratamento, cuja superfície ficou exposta ao impacto das gotas de chuva eao escoamento superficial, provavel mente sofrendo o colapso estrutural dos agregados, com conseqüente sel amento eencrostamento superficiais, refl etindo-se na redução da infiltração e no aumento da erosão hídrica.

A importância dos efeitos do cultivo do solo na erosão hídrica pode ser constatada, comparando os tratamentos aração + duas gradagens, tanto na rotação quanto na sucessão, com o sol o sem cultura preparado com aração + duas gradagens, os quais tiveram o mesmo sistema de preparo, diferindo apenas quanto aos cultivos. Assim, o sistema aração + duas gradagens, envol vendo cultivos, cujos resíduos da parte aérea foram incorporados juntamente com as raízes, provavel mente mel horou a estrutura do solo. Na média da rotação e sucessão de culturas, o sistema aração + duas gradagens reduziu as perdas de sol o em $93 \%$ em relação ao solo sem cultura com aração + duas gradagens, o que concorda com Bertol (1994), Bertol et al. (1997) e Hernani et al. (1997).

As perdas de solo na aração+duas gradagens foram, em termos gerais, cerca de 1,5 e 3 vezes maiores do que aquelas ocorridas na escarificação + gradagem e semeadura direta, respectivamente (Quadro 4), o que também foi verificado por Eltz et al. (1984), Dedecek et al. (1986) e Bertol et al. (1997), sendo explicadas pelo distinto grau de mobilização do solo ocasionado pelos diferentes preparos. À medida que aumentou a intensidade do preparo, diminuíram a cobertura do solo (Quadro 2) e a rugosi dade superficial (Quadro 3). Isto aumentou a quantidade de partículas prontamente disponíveis para otransporte e a susceti bilidade do sol o à erosão em sulcos pela enxurrada (Cogo, 1981).

A semeadura direta foi o tratamento mais eficaz no controle da erosão, com perdas de solo da ordem de duas e três vezes menores do que aquelas da escarificação + gradagem earação + duas gradagens, respectivamente, na média da rotação e sucessão de culturas (Quadro 4), o que concorda com dados obtidos por Eltz et al . (1984), Bertol (1994) e Hernani et al. (1997). A eficácia desse sistema de manejo na redução da er osão pode ser atribuída à cobertura do solo pelos resíduos culturais (Quadro 2), os quais dissi parama energia cinética da chuva e enxurrada, reduzindo sua capacidade de desagregação e transporte. Além disso, os resíduos provavel mente funcionaram como um filtro, retendo os sedimentos e evitando seu transporte para fora da área.

A rotação de culturas reduziu as perdas de solo em 43,35 e $20 \%$ nos tratamentos aração + duas gradagens, escarificação + gradagem e semeadura

Quadro 4. Erosividade $\left(\mathrm{EI}_{30}\right)$ e perdas de solo por escoamento superficial, determinadas em diferentes sistemas de cultivo, preparo do solo(1), ti pos de culturas e períodos de avaliação, entre 1993 e 1998, num Cambissolo Húmico alumínico em Lages (SC)

\begin{tabular}{|c|c|c|c|c|c|c|c|c|}
\hline \multirow{3}{*}{ Tipo de cultura } & \multicolumn{7}{|c|}{ Perda de solo } & \multirow{3}{*}{$\begin{array}{c}\text { Erosividade } \\
\text { (E I 30) }\end{array}$} \\
\hline & \multicolumn{3}{|c|}{ R otação de culturas } & \multicolumn{3}{|c|}{ Sucessão de culturas } & \multirow{2}{*}{$\begin{array}{c}\text { Solo sem cultura } \\
\text { (média de duas parcelas) }\end{array}$} & \\
\hline & SDI & $\mathbf{E}+\mathbf{G}$ & $\mathbf{A}+\mathbf{G}$ & SDI & $\mathbf{E}+\mathbf{G}$ & $\mathbf{A}+\mathbf{G}$ & & \\
\hline & \multicolumn{7}{|c|}{$-\mathrm{t} \mathrm{ha}^{-1}$} & MJ $m m h^{-1} h^{-1}$ \\
\hline Soja e Soja(2) & 0,02 & 0,05 & 0,11 & 0,02 & 0,06 & 0,14 & 3,24 & 2.496 \\
\hline Trigo e Aveia preta(3) & 0,84 & 1,50 & 3,01 & 0,49 & 2,09 & 4,17 & 56,59 & 2.659 \\
\hline Soja e Feijão(4) & 0,09 & 0,29 & 2,66 & 0,18 & 0,53 & 3,67 & 37,35 & 4.050 \\
\hline Trigo e Ervilhaca comum(5) & 0,10 & 0,10 & 0,17 & 0,08 & 0,21 & 0,21 & 3,08 & 1.109 \\
\hline Soja e Milho(6) & 0,23 & 0,59 & 0,33 & 0,21 & 0,86 & 0,58 & 2,82 & 1.469 \\
\hline Trigo e Ervilhaca comum(7) & 0,08 & 0,34 & 0,18 & 0,09 & 0,35 & 0,21 & 2,08 & 713 \\
\hline Soja e Soja(8) & 0,37 & 1,74 & 1,63 & 0,50 & 1,53 & 2,35 & 83,78 & 4.700 \\
\hline Trigo e Trigo ${ }^{(9)}$ & 0,41 & 2,43 & 1,40 & 0,41 & 2,08 & 3,73 & 5,39 & 1.206 \\
\hline Soja e F eijão(10) & 0,26 & 0,48 & 0,63 & 0,25 & 0,71 & 0,93 & 73,49 & 4.098 \\
\hline Trigo e Nabo forragei ro(11) & 0,45 & 0,26 & 1,41 & 0,58 & 0,76 & 2,04 & 14,39 & 3.185 \\
\hline Soja e Milho(12) & 3,97 & 6,10 & 6,50 & 4,27 & 10,70 & 11,88 & 111,83 & 4.742 \\
\hline Trigo e Aveia preta(13) & 1,15 & 0,92 & 2,27 & 2,84 & 2,97 & 5,65 & 26,40 & 2.120 \\
\hline Média & 0,66 & 1,23 & 1,69 & 0,83 & 1,90 & 2,96 & 35,04 & 2.712 \\
\hline Desvio-Padrão & 1,05 & 1,62 & 1,74 & 1,60 & 2,79 & 3,21 & 21,21 & 1.376 \\
\hline C.V. (\%) & 159 & 132 & 103 & 193 & 146 & 108 & 61 & 51 \\
\hline
\end{tabular}

(1)Sistemas de preparo do solo: SDI - semeadura direta; E + G - escarificação + gradagem; A + G - aração + duas gradagens. ${ }^{(2)} 01 / 01 / 93$ a 08/06/93; (3)09/06/93 a 17/11/93; ${ }^{(4)} 18 / 11 / 93$ a 12/07/94; ${ }^{(5)} 13 / 07 / 94$ a 18/11/94; ${ }^{(6)} 19 / 11 / 94$ a 30/07/94; ${ }^{(7)} 01 / 08 / 95$ a 30/11/95; ${ }^{(8)} 01 / 12$ / 95 a 30/04/96; ${ }^{(9)} 01 / 05 / 96$ a 15/11/96; ${ }^{(10)} 15 / 11 / 96$ a 30/04/97; ${ }^{(11)} 01 / 05 / 97$ a $15 / 11 / 97 ;{ }^{(12)} 16 / 11 / 97$ a $30 / 04 / 98 ;{ }^{(13)} 01 / 05 / 98$ a 30/10/98. 
direta, respectivamente, em relação à sucessão de culturas, na média do período de estudo (Quadro 4), concordando com dados obtidos por Lombardi Neto (1994). Este comportamento pode ser explicado pela alternância das culturas e práticas culturais na rotação, com conseqüente manutenção de cobertura vegetal variada e uniforme e elevado conteúdo de matéria orgânica, refletindo-se nas propriedades físicas dosolo e, geralmente, na erosão(Uhland, 1949; Moldenhauer et al., 1967; Lombardi N eto, 1994).

A maior redução nas perdas de solo ocasionada pela rotação de culturas ocorreu na aração + duas gradagens, e a menor, na semeadura direta. Isso demonstra que o efeito da rotação é mais expressivo nos sol os mais intensamente revolvidos e com menor cobertura, possivelmente em face da melhoria da estrutura proporcionada pela rotação em relação à sucessão, na qual a menor diversidade de culturas e resíduos beneficia menos as propriedades físicas do solo do que a rotação.

O sistema de preparo teve um efeito mais expressivo do que o sistema de cultivo sobre as perdas de solo. Enquanto a rotação de culturas diminuiu as perdas de solo em $37 \%$ em relação à sucessão, na média dos sistemas de preparo, a semeadura direta diminuiu as referidas perdas em $68 \%$ em relaçãoà aração +duas gradagens, na média da rotação e sucessão de culturas (Quadro 4). I sto pode ser explicado pelas prováveis alterações provocadas na estrutura do solo pelo preparo convencional (Cogo, 1981), bem como pela incorporação dos resíduos culturais com conseqüente diminuição da cobertura do solo, deixando-o exposto ao impacto das gotas de chuva e escoamento superficial, favorecendo a erosão hídrica (Cogo, 1981). Dessa forma, a não-mobilização do solo e a manutenção dos resíduos culturais sobrea superfíciena semeadura direta foram responsáveis por reduções nas perdas de solo mais expressivas do que aquelas devidas à mel horia da estrutura do sol o originadas pela adoção da rotação de culturas.

Em geral, as perdas desol ovariaram amplamente entre os períodos de cultivo, de acordo não só com a variação na erosi vidade das chuvas (Quadro 4), mas também com a variação no tipo de cultura e na umidade do solo de um período a outro.

As perdas deágua (Quadro 5), em geral, seguiram a mesma tendência das perdas desolo. Os tratamentos aração + duas gradagens, escarificação + gradagem e semeadura direta promoveram reduções nas perdas de água de 27, 61 e 67\%, respectivamente, em relação ao solo sem cultura com aração + duas gradagens, na média da rotação e sucessão de culturas. Tais reduções foram menores do que aquelas observadas nas perdas de sol o, o quetambém foi verificado por Cogo (1981), Bertol (1994) e Bertol et al. (1997), podendo ser explicadas pel o fato de o solo, independentemente do sistema de preparo,

\section{Quadro 5. Ocorrência de chuva e fração da água pluvial perdida nos diferentes sistemas e períodos de cultivo, preparo do solo ${ }^{(1)}$ e ti pos de culturas estudadas, entre 1993 e 1998, num Cambissolo Húmico alumínico em Lages (SC)}

\begin{tabular}{|c|c|c|c|c|c|c|c|c|}
\hline \multirow{3}{*}{ Tipo de cultura } & \multicolumn{7}{|c|}{ Perda de água } & \multirow{3}{*}{ Chuva } \\
\hline & \multicolumn{3}{|c|}{ R otação de culturas } & \multicolumn{3}{|c|}{ Sucessão de culturas } & \multirow{2}{*}{$\begin{array}{c}\text { Solo sem cultura } \\
\text { (média de duas parcelas) }\end{array}$} & \\
\hline & SDI & $\mathbf{E}+\mathbf{G}$ & $\mathbf{A}+\mathbf{G}$ & SDI & $\mathbf{E}+\mathbf{G}$ & $\mathbf{A}+\mathbf{G}$ & & \\
\hline & & & & $-\mathrm{mr}$ & $m^{-1}-$ & & & $\mathrm{mm}$ \\
\hline Soja e Soja(2) & 2,3 & 2,5 & 6,6 & 3,6 & 5,2 & 6,2 & 29,9 & 593 \\
\hline Trigo e Aveia preta(3) & 238,8 & 192,9 & 236,8 & 78,6 & 141,0 & 41,5 & 303,2 & 663 \\
\hline Soja e F eijão(4) & 43,7 & 98,7 & 158,0 & 28,6 & 84,7 & 136,7 & 245,0 & 950 \\
\hline Trigo e Ervilhaca comum(5) & 37,5 & 31,6 & 40,8 & 9,3 & 40,0 & 12,1 & 133,1 & 446 \\
\hline Soja e Milho(6) & 4,8 & 9,6 & 5,1 & 3,6 & 11,0 & 9,1 & 31,5 & 554 \\
\hline Trigo e Ervil haca comum ${ }^{(7)}$ & 7,3 & 74,0 & 29,5 & 5,6 & 17,7 & 7,1 & 116,4 & 393 \\
\hline Soja e Soja ${ }^{(8)}$ & 10,3 & 67,2 & 62,8 & 11,8 & 67,3 & 150,2 & 298,5 & 792 \\
\hline Trigo e Trigo9) & 37,0 & 82,2 & 54,1 & 16,0 & 69,8 & 102,5 & 140,2 & 703 \\
\hline Soja e Feijão(10) & 132,8 & 161,4 & 194,5 & 129,6 & 182,5 & 263,2 & 332,8 & 791 \\
\hline Trigo e Nabo forragei ro ${ }^{(11)}$ & 136,1 & 26,7 & 309,5 & 132,7 & 183,4 & 446,7 & 325,5 & 1.022 \\
\hline Soja e Milho(12) & 128,9 & 114,7 & 214,5 & 119,5 & 223,0 & 510,4 & 343,9 & 1.035 \\
\hline Trigo e Aveia preta(13) & 128,0 & 93,0 & 215,0 & 330,0 & 187,0 & 400,0 & 429,0 & 895 \\
\hline Média & 75,6 & 79,5 & 127,3 & 72,4 & 101,1 & 173,8 & 238,0 & 736 \\
\hline Desvio-padrão & 72,1 & 55,9 & 100,8 & 91,8 & 75,1 & 178,1 & 127,0 & 206 \\
\hline C.V. (\%) & 95 & 70 & 79 & 127 & 74 & 102 & 53 & 28 \\
\hline
\end{tabular}

(1)Sistemas de preparo do solo: SDI - semeadura direta; E + G - escarificação + gradagem; A + G - aração + duas gradagens. ${ }^{(2)} 01 / 01 /$

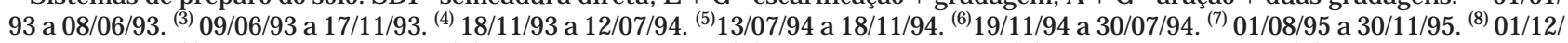
95 a 30/04/96. . ${ }^{(9)} 01 / 05 / 96$ a 15/11/96. ${ }^{(10)} 15 / 11 / 96$ a 30/04/97. ${ }^{(11)} 01 / 05 / 97$ a 15/11/97. ${ }^{(12)} 16 / 11 / 97$ a 30/04/98. ${ }^{(13)} 01 / 05 / 98$ a 30/10/98. 
apresentar limitada capacidade de infiltração, a partir da qual a taxa de enxurrada tende a igualarse em distintos sistemas de preparo (Bertol, 1994). Isto, juntamente com o volume anual de chuvas, explica, parcialmente, a menor variabilidade ocorrida nas perdas deágua entre períodos de cultivo do que nas perdas de solo. As menores perdas de água foram observadas na semeadura direta e escarificação + gradagem, as quais foram semel hantes entresi. A cobertura do sol o pel os resíduos culturais (Quadro 2) protegeu a superfície contra o impacto das gotas de chuva e escoamento superficial, diminuindo também a velocidade da enxurrada emantendo altas taxas deinfiltração deágua no solo nesses tratamentos.

A erosividade das chuvas na primavera-verãofoi, em média, cerca de duas vezes maior do que no outono-inverno (Quadro 6). No entanto, as perdas de solo dos tratamentos com preparo e submetidos ao cultivo não sofreram influência da estação do ano nessa mesma proporção. Embora no período de primavera-verão tenha sido maior, a erosividade concentrou-se principalmente nos meses de janeiro e fevereiro, coincidindo com o período de pleno desenvolvimento das culturas, o que certamente contribuiu para a minimização do seu efeito sobrea erosão. Isto é reforçado pelo fato de terem sido as perdas de solo no tratamento aração + duas gradagens e solo sem cultura cerca de três vezes maiores na primavera-verão do que no outonoinverno, de acordo, portanto, com a diferença na erosividade das chuvas entre os dois períodos. Em ambos os períodos, as perdas de água diminuíram com a intensidade de preparo do solo, o que está relacionado com a rugosidade, cobertura eestrutura do solo. Assim, o menor revolvimento do solo dos sistemas de preparo conservacionistas (semeadura direta e escarificação + gradagem), com maiores coberturas e, ou, rugosidades superficiais, propiciou a diminuição das perdas de sol o e água.

\section{CONCLUSÕES}

1. A semeadura direta é mais eficaz no controle das perdas de solo, reduzindo-as em 68 e 52\% em

Quadro 6. Valores médios, envolvendo rotação e sucessão de culturas, das perdas de solo e de água nas diferentes estações do ano, sistemas de preparo do solo ${ }^{(1)}$ e ciclos culturais; erosividade $\left(\mathrm{EI}_{30}\right)$ e chuva, num Cambissolo Húmico alumínico em Lages (SC)

\begin{tabular}{|c|c|c|c|c|c|c|c|c|c|c|}
\hline \multirow{2}{*}{ Ciclo cultural } & \multicolumn{4}{|c|}{ Perda de solo } & \multirow{2}{*}{$\begin{array}{l}\text { Erosividade } \\
\quad\left(\mathrm{EI}_{30}\right)\end{array}$} & \multicolumn{4}{|c|}{ Perda de água } & \multirow{2}{*}{ Chuva } \\
\hline & SDI & $\mathbf{E}+\mathbf{G}$ & $\mathbf{A}+\mathbf{G}$ & SSC & & SDI & $\mathbf{E}+\mathbf{G}$ & $\mathbf{A}+\mathbf{G}$ & SSC & \\
\hline & \multicolumn{4}{|c|}{ t ha-1 } & MJ $m m ~ h a^{-1} h^{-1}$ & \multicolumn{4}{|c|}{$-\mathrm{mm} \mathrm{m}^{-1}$} & $\mathrm{~mm}$ \\
\hline \multicolumn{11}{|c|}{ Primavera-verão } \\
\hline $\begin{array}{l}\text { Soja e Soja(2) } \\
\text { Soja e Feijão(4) } \\
\text { Soja e Milho(6) } \\
\text { Soja e Soja(8) } \\
\text { Soja e Feijão(10) } \\
\text { Soja e Milho(12) }\end{array}$ & $\begin{array}{l}0,02 \\
0,14 \\
0,22 \\
0,44 \\
0,26 \\
4,12\end{array}$ & $\begin{array}{l}0,06 \\
0,41 \\
0,73 \\
1,64 \\
0,60 \\
8,40\end{array}$ & $\begin{array}{l}0,13 \\
3,17 \\
0,46 \\
1,99 \\
0,78 \\
9,19\end{array}$ & $\begin{array}{r}3,24 \\
37,35 \\
2,82 \\
83,78 \\
73,49 \\
111,83\end{array}$ & $\begin{array}{l}2.496 \\
4.050 \\
1.469 \\
4.700 \\
4.098 \\
4.742\end{array}$ & $\begin{array}{r}3,0 \\
36,2 \\
4,2 \\
11,1 \\
131,2 \\
124,2\end{array}$ & $\begin{array}{r}3,9 \\
91,7 \\
10,3 \\
67,3 \\
172,0 \\
168,9\end{array}$ & $\begin{array}{r}6,4 \\
147,4 \\
7,1 \\
106,5 \\
228,9 \\
362,5\end{array}$ & $\begin{array}{r}29,9 \\
245,0 \\
31,5 \\
298,5 \\
332,8 \\
343,9\end{array}$ & $\begin{array}{r}593 \\
950 \\
554 \\
792 \\
791 \\
1.035\end{array}$ \\
\hline Média & 0,86 & 1,97 & 2,62 & 52,08 & 3.593 & 51,6 & 85,7 & 143,1 & 213,6 & 786 \\
\hline Desvio-padrão & 1,46 & 2,91 & 3,11 & 39,07 & 1.206 & 54,9 & 106,7 & 125,2 & 133,1 & 173 \\
\hline C.V. (\%) & 170 & 148 & 119 & 75 & 34 & 106 & 125 & 87 & 62 & 22 \\
\hline \multicolumn{11}{|c|}{ Outono-inverno } \\
\hline $\begin{array}{l}\text { Trigo e Aveia preta(3) } \\
\text { Trigo e Ervilhaca(5) } \\
\text { Trigo e Ervilhaca(7) } \\
\text { Trigo e Trigo(9) } \\
\text { Trigo e Nabo forragei ro(11) } \\
\text { Trigo e Aveia preta(13) }^{(1)}\end{array}$ & $\begin{array}{l}0,67 \\
0,09 \\
0,09 \\
0,41 \\
0,52 \\
2,00\end{array}$ & $\begin{array}{l}1,80 \\
0,16 \\
0,35 \\
2,26 \\
0,51 \\
1,95\end{array}$ & $\begin{array}{l}3,59 \\
0,19 \\
0,20 \\
2,57 \\
1,73 \\
3,96\end{array}$ & $\begin{array}{r}56,59 \\
3,08 \\
2,08 \\
5,39 \\
14,39 \\
26,40\end{array}$ & $\begin{array}{r}2.659 \\
1.109 \\
713 \\
1.206 \\
3.185 \\
2.120\end{array}$ & $\begin{array}{r}158,7 \\
23,4 \\
6,5 \\
26,5 \\
134,4 \\
229,0\end{array}$ & $\begin{array}{r}167,0 \\
35,8 \\
45,9 \\
76,0 \\
105,1 \\
140,0\end{array}$ & $\begin{array}{r}139,2 \\
26,5 \\
18,3 \\
78,3 \\
378,1 \\
307,5\end{array}$ & $\begin{array}{l}303,2 \\
133,1 \\
116,4 \\
140,2 \\
325,5 \\
429,0\end{array}$ & $\begin{array}{r}663 \\
446 \\
393 \\
703 \\
1.022 \\
895\end{array}$ \\
\hline Média & 0,63 & 1,17 & 2,04 & 17,99 & 1.832 & 96,4 & 94,9 & 158,0 & 241,2 & 687 \\
\hline Desvio-padrão & 0,65 & 0,85 & 1,49 & 19,18 & 891 & 82,9 & 47,6 & 138,0 & 118,1 & 224 \\
\hline C.V. (\%) & 103 & 73 & 73 & 107 & 49 & 86 & 50 & 87 & 49 & 33 \\
\hline
\end{tabular}

(1) Sistemas de preparo do sol o: SDI - semeadura direta; E +G - escarificação +gradagem; A +G - aração +duas gradagens; SSC - solo sem cultura preparado com aração +duas gradagens. ${ }^{(2)} 01 / 01 / 93$ a 08/06/93. ${ }^{(3)} 09 / 06 / 93$ a $17 / 11 / 93 .{ }^{(4)} 18 / 11 / 93$ a 12/07/94. ${ }^{(5)} 13 / 07 /$

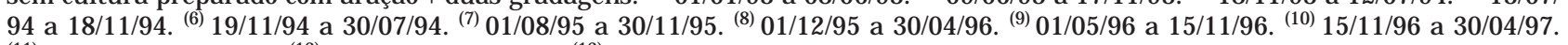
(11) $01 / 05 / 97$ a $15 / 11 / 97 .{ }^{(12)} 16 / 11 / 97$ a $30 / 04 / 98 .{ }^{(13)} 01 / 05 / 98$ a $30 / 10 / 98$. 
relação à aração + duas gradagens e escarificação + gradagem, respectivamente, na média da rotação e sucessão de culturas; as perdas de água seguem a mesma tendência, no entanto, essas são menos influenciadas do que as perdas de solo.

2. Na média dos tratamentos de preparo do solo, a rotação de culturas reduz as perdas de solo em $37 \%$ em relação à sucessão; a maior redução ocorre na aração + duas gradagens, com 43\%; as perdas de água praticamente não são influenciadas pelo sistema de cultivo.

3. O sistema de preparo do solo apresenta maior eficácia na redução das perdas de solo eágua do que o sistema de cultivo.

4. A perda de soloé $63 \%$ menor no outono-inverno do que na primavera-verão, na média geral dos tratamentos de preparo; a maior diferença ocorre no solo sem cultura, com $65 \%$ de redução; para os tratamentos com culturas, no entanto, a redução média das perdas de sol o no outono-inverno é de $29 \%$ em relação à primavera-verão.

5. Na primavera-verão, a aração + duas gradagens mantida livre de cobertura vegetal apresenta perdas de solo cerca de 30 vezes maior do que a média dos demais tratamentos; no outono-inverno, no entanto, esta diferença é da ordem de 14 vezes; as perdas de água são pouco influenciadas pela estação do ano.

\section{LITERATURA CITADA}

ALLMARAS, R.R.; BURWELL, R.E.; LARSON, W.E.; HOLT, R.F. $\&$ NELSON, W.W. Total porosity and random roughness of theinterrow zoneas influenced by tillage. Washington, U.S. Departament of Agriculture, 1966. 22p. (Conservation Research Report, 7)

BERTOL, I. E rosão hídrica em cambissol o húmico distrófico sob diferentes preparos do solo e rotação de cultura. R. Bras. Ci. Solo, 18:267-271, 1994.

BERTOL, I. Comprimento crítico de declive para preparos conservacionistas de solo. Porto Alegre, Universidade Federal do Rio Grande do Sul, 1995. 185p. (Tese de Doutorado)

BERTOL, I.; COGO, N.P. \& LEVIEN, R. Erosão hídrica em diferentes preparos do solo logo após as col heitas de milho e trigo, na presença e ausência dos resíduos culturais. R. Bras. Ci. Solo, 21:409-418, 1997.

BURWELL, R.E.; ALLMARAS, R.R. \& AMEMIYA, M.A. Field measurement of total porosity and surface microrelief of soils. Proc. Soil Sci. Soc. Am., 27:697-700, 1963.

CARVALHO, F.L.C.; COGO, N.P. \& LEVIEN, R. Eficácia relativa de doses e formas de manejo do resíduo cultural de trigo na redução da erosão hídrica do solo. R. Bras. Ci. Solo, 13:251-257, 1990.

CATANEO, A.; CASTRO FILHO, C. \& ACQUAROLE, R.M. Programa para cálculo deíndices de erosividade das chuvas. R. Bras. Ci. Solo, 6:236-239, 1982.
COGO, N.P. U ma contribuiçãoà metodol ogia de estudo das perdas de erosão em condições de chuva natural. I. Sugestões gerais, medição dos volumes, amostragem e quantificação de solo e água da enxurrada (1a aproximação). In: ENCONTRO NACIONAL DE PESQUISA SOBRE CONSERVAÇÃO DO SOLO, 2., Passo Fundo, 1978. Anais. Passo Fundo, EMBRAPA-CNPT, 1978. p.75-98.

COGO, N.P. Effect of residue cover, tillage induced roughness, and slope length on erosion and related parameters. West Lafayette, Purdue University, 1981. 346p. (Tese de Doutorado)

COGO, N.P.; MOLDENHAUER, W.C. \& FOSTER, G.R. Soil loss reductions from conservation tillage practices. Soil Sci. Soc. Am. J ., 48:368-373, 1984.

DEDECEK, R.A.; RESCK, D.V.S. \& DE FREITAS J r., E. Perdas de solo, água e nutrientes por erosão em Latossolo Vermelho-Escuro nos cerrados em diferentes cultivos sob chuva natural . R. Bras. Ci. Solo, 10:265-272, 1986.

DISSMEYER, G.E. \& FOSTER, G.R. Estimating the cover management factor $(C)$ in the universal soil loss equation for forest conditions. J. Soil Water Conserv., 36:235-240, 1981.

ELTZ, F.L.F.; CASSOL, E.A. \& GUERRA, M.\&. ABRÃO, P.U.R. Perdas de solo e água por erosão em diferentes sistemas de manejo e coberturas vegetais em um solo São Pedro (Podzólico Vermel ho-Amarelo) sob chuva natural. R. Bras. Ci. Solo, 8:245-249,1984.

FOSTER, G.R. Modeling the erosion process. In: BASSELMAN, J .A. Hydrological modeling of small watersheds. St. J oseph, American Society of Agricultural Engeeniring, 1982. p.297300.

FOSTER, G.R.; MCCOOL, D.K.; RENARD, K.G. \& MOLDENHAUER, W.C. Conversion of the universal soil loss equation toSI metricunits. Soil Water Conserv., 36:355359, 1981.

HARTWING, R.O. \& LAFLEN, I.M. A meterstick method for measuring crop residue cover J . Soil Water Conserv., 33:9091, 1978.

HERNANI, L.C.; SALTON, J.C.; FABRÍCIO, A.C.; DEDECEK, R. $\&$ ALVES J r., M. Perdas por erosão erendimentos de soja e detrigo em diferentes sistemas de preparo de um $L$ atossolo Roxo de Dourados (MS). R. Bras. Ci. Solo, 21:667-676, 1997.

KUIPERS, H. A relief meter of soil cultivation studies. Neth. J . Agric. Sci., 5:255-262, 1957.

LOMBARDI NETO, F. Práticas de manejo e conservação do solo. In: REUNIÃO BRASILEIRA DE MANEJO E CONSERVAÇÃO DO SOLO E DA ÁGUA, 10., Florianópolis, 1994. Resumos. Florianópolis, Sociedade Brasileira de Ciência do Solo, 1994. p.111-119.

MARIA, I.C. Cálculo da erosividade da chuva. In: LOMBARDI NETO, F.; CASTRO, O.M.; DECHEN, S.C.F.; VIEIRA, S.R. \& MARIA, I.C. Manual de programas de processamento de dados de campo e de laboratório para fins de experimentação em conservação do solo. Campinas, Instituto Agronômico de Campinas, 1994. Não publicado 
MOLDENHAUER, W.C.; WISCHMEIER, W.H. \& PARKER, D.T. The influence of crop management on runoff, erosion and soil properties of a Marshall silty clay loam. Soil Sci. Soc. Am. Proc., 31:541-546, 1967.

RÖMKENS, M.J .M. \& WANG, J .Y. Soil roughness changes from rainfall. Trans. Am.Soc. Agr. Eng., 30:101-107, 1987.

UHLAND, R.E. The value of crops rotations for soil and water conservation. In: USDA. Soil conservation service. Washington, 1949. (SCSTP, 83)
WISCHMEIER, W.H. A rainfall erosion index for a universal soil loss equation. Proc. Soil Sci. Soc. Am., 23:246-249, 1959.

WISCHMEIER, W.H. \& SMITH, D.D. Rainfall energy and its relationship to soil loss. Trans. Am. Geophys. Union, 39:285291, 1958.

WISCHMEIER, W.H. \& SMITH, D.D. Predicting rainfall erosion Iosses: a guide to conservation planning. Washington, USDA, 1978. 58p. (Agricultural Handbook, 537) 